\title{
Nutrition, sex, gestational age, and hair growth in babies
}

\author{
H. M. BERGER, J. KING, S. DOUGHTY, AND B. A. WHARTON \\ From the Special Care Baby Unit, Sorrento Maternity Hospital, Birmingham
}

SUMMARY Hair growth measurements are a sensitive indicator of nutrition and we have assessed their value in the perinatal period. The proportion of growing roots and their diameter were studied at birth in 114 babies and repeated 3 weeks later in 29 low birthweight babies. Intrauterine malnutrition resulted in thinner roots but the changes after birth were not related to nutrition and these measurements will not be useful in feeding studies in this period. At birth, gestational age and sex affected the hair root, and it may be important to recognise these differences if the hair root is used in biochemical screening tests. We have used a new simple technique for measuring the root diameter using an image-splitting eye-piece.

Hair, one of the fastest growing tissues, is rapidly affected by nutritional and endocrine changes (Platt, 1965) and recently quantitative measurements of hair root morphology have been used to study nutrition in children and adults (Bradfield et al., 1968; Bradfield, 1971). We planned this study to assess whether these measurements were also a sensitive indicator of nutrition in newborn babies and to determine what other factors affected hair growth in this period.

\section{Patients}

Hair samples were collected at birth from 114 babies born at this hospital after informed consent had been obtained from the mother. (a) 46 term babies (23 boys, 23 girls): gestation assessed at 37-41 completed weeks by mother's dates and confirmed by paediatrician's assessment (Dubowitz et al., 1970); appropriate weight for gestation, i.e. weight between 5th and 95th centiles (Tanner and Thomson, 1970). 18 of these babies were Asian and the others European. (b) 38 preterm babies ( 22 boys, 16 girls): gestation 36 weeks or less, appropriate weight for gestation. 7 Asians, 31 Europeans. (c) 30 light for dates, term babies ( 11 boys, 19 girls): gestation $37-41$ weeks, weight for gestational age below 5th centile. 13 Asians, 17 Europeans.

A further sample of hair was collected in 14 preterm and 15 light-for-dates babies at 21 days of age. They were fed on SMA or SMA Gold Cap and had gained weight satisfactorily (mean \pm SD $275 \pm 20 \mathrm{~g}$ ).

Received 22 August 1977

\section{Methods}

Technique. The morphology of hair from the occipital region was studied using a modification of the method described by Bradfield (1972). The occipital area was used because it contains the largest number of growing roots at birth (Pecoraro et al., 1964). A sample of hair was plucked using forceps with a cross-hatched gripping surface. After the distal ends of the shafts of the hairs had been placed between two $\frac{1}{2}$ " adhesive labels they were released from the forceps. The sample was then stored in an air-tight plastic packet until analysis. The samples frequently contained broken shafts, particularly those taken on the 21 st day after birth. Only samples with a minimum of 8 intact roots on day 1 , or 5 intact roots on day 21 , have been included in the results. The mean $(+S D)$ number of hair roots analysed was $28 \pm 14$.

Measurements. The sample, still attached to the label, was dipped into water and then slid into a Fuchs Rosenthal red cell counting chamber (depth $0.2 \mathrm{~mm}$ ) already filled with water. The sample was then examined in two ways using a monocular microscope. (a) Under $\times 24$ magnification all the roots were classified as growing (anagen) or resting (telogen) (see Fig. 1a). The number of anagens present was then expressed as a percentage of the total number of hair roots. (b) The diameter of the anagen roots was then measured. Whenever possible 10 anagens were measured, and only samples with at least 5 anagens were included in the results on the root diameter. The diameter was measured using a 
Vickers AEI image-splitting eye-piece at $\times 60$ magnification.

This method was adopted because it was easier than using a graticule or filar micrometer as any root in the field of the objective lens could be measured without moving the hair to a reference line. Turning the micrometer screw on the side of the eye piece split each root into a red and green image (see Fig. 1b) and when their edges were just touching, the measurement was taken on the digital readout of the eye piece. This had been calibrated using a stage micrometer.

Statistics. (a) The percentage of anagens was compared using the Wilcoxon Ranking test. (b) Student's $t$ test was used for the hair root diameters.

\section{Results}

At birth.

Hair root diameter (Fig. 2). The diameter increased as gestation advanced so that term babies had significantly thicker roots than preterm babies. The roots of these term babies were also significantly thicker than those of the light-for-dates babies. There was no difference between Asians and Europeans. The mean root diameter in girls was greater than that in boys but this difference was not significant.
Anagen number (Fig. 3). In these well nourished babies the number of anagens was not related to gestational age in girls but in boys there was a significant decrease as gestation advanced. In well nourished babies the anagen number was high in girls and low in boys (Fig. 4). This difference did

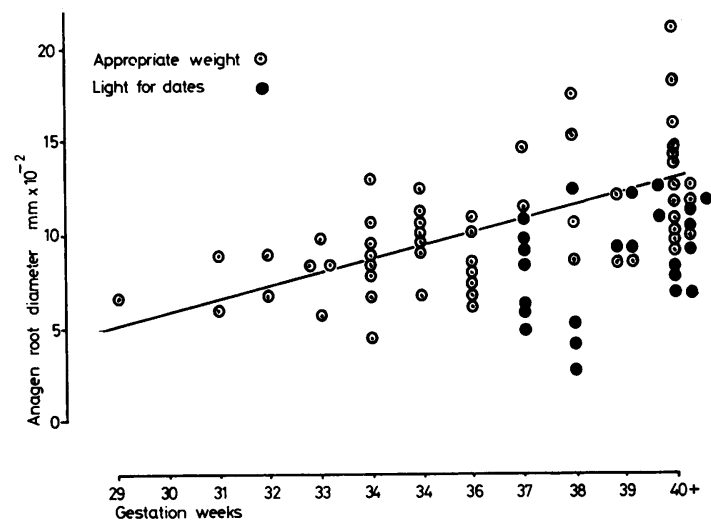

Fig. 2 Hair root diameter at birth. In well nourished babies the diameter increased with gestational age $(r=0.58, P<0.001$ ) so that term babies had thicker roots (mean $+S D, 13 \cdot 2 \pm 3 \cdot 6 \mathrm{~mm} \times 10^{-2}$ ) than preterm babies $(9 \cdot 1 \pm 2 \cdot 0, P<0 \cdot 001)$. The roots of these term babies were also thicker than those of the light-for-dates babies $(8 \cdot 3 \pm 3 \cdot 0, P<0 \cdot 001)$.

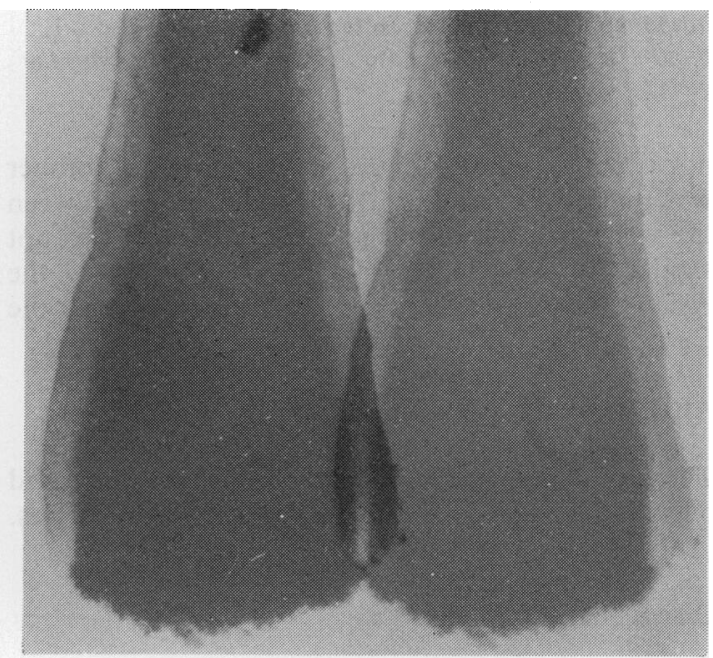

(b)

Fig. 1 (a) The growing root, anagen, on the left, is bell shaped, heavily pigmented, and has a sheath, while the resting root, telogen, on the right, is tear-drop shaped and has lost its sheath and pigmentation. (b) The anagen has been split into two images. The root diameter is measured on the calibrated eye piece dial when the edges of the two images just touch. The sheath is not included in the measurement. 


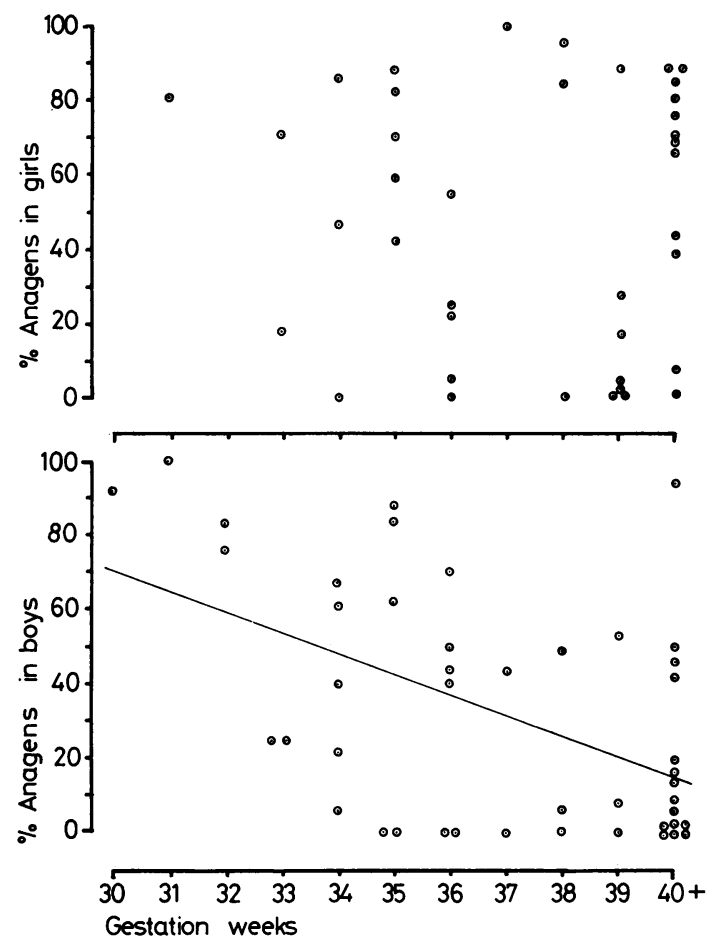

Fig. 3 Number of anagens at birth in babies of appropriate weight for gestation. Advancing gestational age did not affect the number of anagens in girls $(r=-0.05$, not significant) but resulted in a decrease in the number of anagens in the boys $(r=0.52$, $P<0.001)$. At term the boys had fewer anagens than the girls $(P<0 \cdot 05)$.

not occur in light-for-dates babies; anagen number was high in boys and girls. The difference between the well nourished and light-for-dates boys was not significant. The larger number of anagens in the Asians was not significantly different from the Europeans.

\section{After birth.}

The root diameter and number of anagens decreased over the 3 weeks in the 29 low birthweight babies. (Table).

\section{Discussion}

The results showed that during intrauterine life hair growth was affected by the sex, gestational age, and nutritional status of the fetus. After birth the hair root rapidly entered a resting phase. Girls had more growing roots than boys, perhaps due to hormonal differences. During pregnancy when oestrogen levels are high the mother has an increased number of growing hair roots which rapidly revert to the resting phase as oestrogen levels fall in the postpartum period (Lynfield, 1960). On the other hand, testosterone, after conversion in the hair follicle to the active form $5 \alpha$ dihydrotestosterone, inhibits hair growth as in male pattern baldness (Adachi, 1973).

At term boys have a greater plasma testosterone level (Forest et al., 1973), and males appear more able to form $5 \alpha$ dihydrotestosterone in the hair

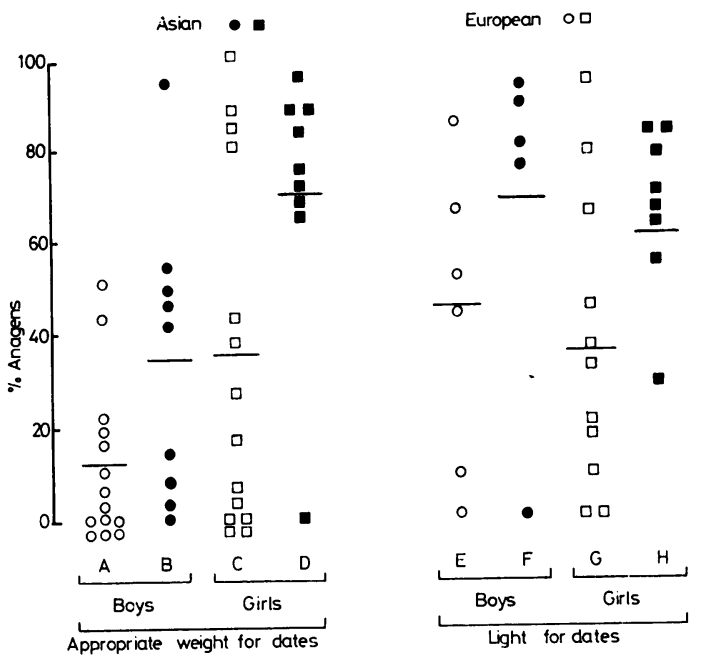

Fig. 4 The number of anagens in term babies. (I) Effect of sex. Appropriate-weight-for-dates boys ( $A$ and $B)$ had fewer anagens than girls $(C$ and $D)(P<0 \cdot 05)$. When further divided into racial groups the difference persisted in the Asian babies $(B$ cf $D)(P<0.05)$ but not in European babies ( $A$ cf $C$ ). (2) Effect of intrauterine nutrition. Light-for-dates boys ( $E$ and $F$ ) had the same anagen number as the girls $(G$ and $H)$. This increase in the anagens in the light-for-dates boys $(E$ and $F)$ was not significantly different from the appropriate-weight-fordates boys ( $A$ and $B$ ). (3) Effect of race. Differences between Asians and Europeans were not statistically significant in any of the groups.

Table Postnatal changes in the number of anagens and their diameter

\begin{tabular}{lrrrr}
\hline Hair measurement & Day I & Day 21 & $P$ & No. of babies* \\
\hline $\begin{array}{l}\text { \% anagens } \\
\text { Mean }\end{array}$ & 51 & 30 & & \\
$\begin{array}{l}\text { Median } \\
\text { Range }\end{array}$ & 62 & 6 & $<0.05 \dagger$ & 29 \\
$\begin{array}{l}\text { Root diameter } \\
\begin{array}{l}\text { Mean }+ \text { SD } \\
\left(m m \times 10^{-2}\right)\end{array}\end{array}$ & $0-100$ & $0-100$ & & \\
\hline
\end{tabular}

*See methods.

†Wilcoxon's rank sum test for pair differences.

†Student's $t$ test on paired observations. 
follicle (Houssay, 1976) so that the resting state of the hair follicles seen more commonly in boys may be a similar phenomenon to male pattern baldness in later life. Such differences between boys and girls were not found by Pecararo et al. (1964) and Kostanecki et al. (1965), but they did not record the race, gestational age, and nutritional state of their babies. Saadat et al. (1976) found similar results to ours in that the babies who had no growing roots at birth were mainly boys, although in their discussion they reached the opposite conclusion.

The number of resting hairs in boys increased as gestation advanced. Plasma testosterone does not increase with gestational age nor is there a decrease in its plasma protein binding (Reyes et al., 1973), but the maturing hair follicle may be more able to convert testosterone to $5 \alpha$ dihydrotestosterone as fetal enzyme systems mature. The increase in hair root diameter with gestational age is similar to the changes in hair shaft diameter found by Baum et al. (1974).

Intrauterine malnutrition affected hair growth, since the light-for-dates babies had thinner roots. Similar changes are seen in postnatal malnutrition (Bradfield et al., 1968) and a thinner shaft diameter has been described by Baum et al. (1974) in malnourished newborns. The effect of intrauterine malnutrition on the number of growing roots was unexpected. In long term postnatal malnutrition the proportion of anagens is reduced (Bradfield $e t$ al., 1968), but in the light-for-dates girls in our study there was no change while in boys the number of growing roots had actually increased. In intrauterine malnutrition the hair follicle may become less responsive to the effect of hormones or, in boys, the hair follicle may no longer be able to convert the testosterone to its tissue active form. The larger number of growing roots seen in the Asians was not significant, but may be worth further study as race affects hair form and distribution (Rook, 1975).

After birth the number of growing roots and their diameter decreased, and this occurred in the preterm and light-for-dates babies even though weight gain was satisfactory. Furthermore, although cystine is a major component of hair we found no relationship between hair growth and cystine concentration in the diet (Berger et al., 1976). These changes may be due to hormonal changes after birth, for example, loss of oestrogen stimulation, rather than to postnatal nutrition. This finding needs to be confirmed in normal term babies since hair loss occurs during the first few months of life (Pecoraro et al., 1964). Technical difficulties may have affected the results. On the first day the hair was moist and often covered in vernix and large samples were obtained, but by 3 weeks the dry hair was brittle so that the more easily plucked resting roots may have contributed excessively to the proportion of intact roots per sample. This, however, would not explain the decreased diameter of the hair roots and we believe the findings do reflect the changes occurring in the scalp.

Clinical implications. Measurement of the hair root and shaft has been used in the assessment of proteincalorie malnutrition in tropical countries. Recently, however, the technique of measurement has been criticised as 'tedious and time consuming' (Johnson et al., 1975). Modification of the technique by using an image-splitting eye-piece allows easier and quicker measurement, and therefore wider application, for example in assessment of failure to thrive or in prediction of poor intrauterine growth by studying maternal hair (Bradfield et al., 1975). It is unlikely to be of use in assessing nutrition in the newborn since many other factors appear to affect hair growth at this time. Hair is increasingly used as a tissue for biochemical investigation of trace elements and enzymes for carrier states. It is important to realise that hair undergoes growth cycles and that in early infancy the resting state may influence the results.

H.M.B. held a Sheldon and a Mary Crosse Clinical Research Fellowship. We thank Mr H. Sharpe and Mr B. Amer for technical assistance; the Department of Medical Illustration, Southmead Hospital; and Mrs H. Bird for typing the manuscript.

\section{References}

Adachi, K. (1973). The metabolism and control mechanisms of human hair follicles. Current Problems in Dermatology, 5, 37-78.

Baum, J. D., Hughes, E. A., and Harris, E. A. (1974). Neonatal hair as a record of intrauterine nutrition. Biology of the Neonate, 25, 208-218.

Berger, H. M., Scott, P. H., Kenward, C., Scott, P., and Wharton, B. A. (1976). Nutritional value of whey protein and curd protein in the low birth weight baby. (Abst.) Archives of Disease in Childhood, 51, 235.

Bradfield, R. B. (1971). Protein deprivation: comparative response of hair roots, serum protein, and urinary nitrogen. American Journal of Clinical Nutrition, 24, 405-410.

Bradfield, R. B. (1972). A rapid tissue technique for the field assessment of protein-calorie malnutrition. American Journal of Clinical Nutrition, 25, 720-729.

Bradfield, R. B., Bailey, M. A., and Cordano, A. (1968). Hair root changes in Andean Indian children during marasmic kwashiorkor. Lancet, 2, 1169-1170.

Bradfield, R. B., Lechtig, A., Allen, L., and Quevedo, C. (1975). Maternal hair roots in prediction of low birth weight risk. Lancet, 2, 928-929.

Dubowitz, L. M. A., Dubowitz, V., and Goldberg, C. (1970). Clinical assessment of gestational age in the newborn infant. Journal of Pediatrics, 77, 1-10.

Forest, M. G., Cathiard, A. M., and Bertrand, J. A. (1973). Evidence of testicular activity in early infancy. Journal of Clinical Endocrinology and Metabolism, 37, 148-151. 
Houssay, A. B. (1976). Effect of anabolic androgenic steroids on the skin, including hair and sebaceous glands. AnabolicAndrogenic Steroids. Handbook of Experimental Pharmacology, Vol. 43, pp. 155-190. Ed. by C. D. Kochakian. Springer, Berlin.

Johnson, A. A., Latham, M. C., and Roe, D. A. (1975). The use of changes in hair root morphology in the assessment of protein-calorie malnutrition. Journal of Investigative Dermatology, 65, 311-314.

Kostanecki, W., Pawlowski, A., and Lozinska, D. (1965). Der Haarwurzelstatus bei Neugeborenen. Archiv für Klinische und Experimentelle Dermatologie, 221, 162-165.

Lynfield, Y. L. (1960). Effect of pregnancy on the human hair cycle. Journal of Investigative Dermatology, 35, 323-327.

Pecoraro, V., Astore, I., and Barman, J. M. (1964). Cycle of the scalp hair of the newborn child. Journal of Investigative Dermatology, 43, 145-147.

Platt, B. S. (1965). Nutritional influences on the skin: experimental evidence. Comparative Physiology and Path- ology of the Skin, pp. 245-272. Ed. by A. J. Rook and G. S. Walton. Blackwell, Oxford.

Reyes, F. I., Winter, J. S. D., and Faiman, C. (1973). Studies on human sexual development. I. Fetal gonadal and adrenal sex steroids. Journal of Clinical Endocrinology and Metabolism, 37, 74-78.

Rook, A. (1975). Hair. II. Racial and other genetic variations in hair form. British Journal of Dermatology, 92, 599-600. Saadat, M., Khan, M. A., Gutberlet, R. L., and Heald, F. P. (1976). Measurements of hair in normal newborns. Pediatrics, 57, 960-962.

Tanner, J. M., and Thomson, M. A. (1970). Standards of birth weight at gestation periods from 32 to 42 weeks, allowing for maternal height and weight. Archives of Disease in Childhood, 45, 566-569.

Correspondence to Dr H. M. Berger, Special Care Baby Unit, Southmead Hospital, Bristol BS10 5NB. 